\title{
THE PROBLEM OF EXPERIMENTAL EVALUATION FOR CORONA RESISTANCE OF VFD CABLES
}

\author{
Andrey P. Leonov ${ }^{1}$, and Dmitry I. Charkov ${ }^{1, *}$ \\ ${ }^{1}$ National Research Tomsk Polytechnic University, 634050, Tomsk, Russia
}

\begin{abstract}
This article describes an approach for evaluating experimental cable insulation resistance electro-thermal aging, typical for the drive frequency being adjusted. It estimates the average time until the insulation breakdown when exposed to a sample of high electrical loads. The possibility for an adequate choice of insulating materials, which are used in the insulation of VFD cable and shown ways to improve testing methods.
\end{abstract}

\section{Introduction}

When using a VFD on the basis of pulse-width modulation having electro-thermal aging. This reduces the life of the insulation of supply cables and reduce the reliability of the entire system. [1]

The nature and magnitude of operating voltages in the VFD depends on the length of the supply cable [2], the method of modulation voltage [3], the stator winding structure, composition and parameters of elements in the VFD. With that said insulated power cables for variable frequency drive to withstand higher operating load for the entire lifetime. First of all it is determined by the ability of insulation to withstand the action of electric discharges [4].

\section{Experimental part}

The work carried out to determine the average time of the breakdown products of cable samples with an extruded polymeric insulation.

The objects of study are the samples were insulated from the block copolymer, ethylene-propylene, polyurethane and polyethylene. Samples for testing are to a twists wire with a working area of $125 \mathrm{~mm}$.

The samples were placed in an oven heated to a temperature class Insulation, kept up to breakdown when exposed to a sample of the AC voltage. It has been tested several batches

\footnotetext{
*Corresponding author: dic1@tpu.ru
} 
of twist at different temperatures, under the influence of an elevated voltage and power frequency.

\section{Experimental results}

The results showed: when the frequency of the applied field surface discharges reduce the mean time to breakdown (Figure 1). This is due to the fact that increased heterogeneity of the field and the intensity of any electrical discharges.

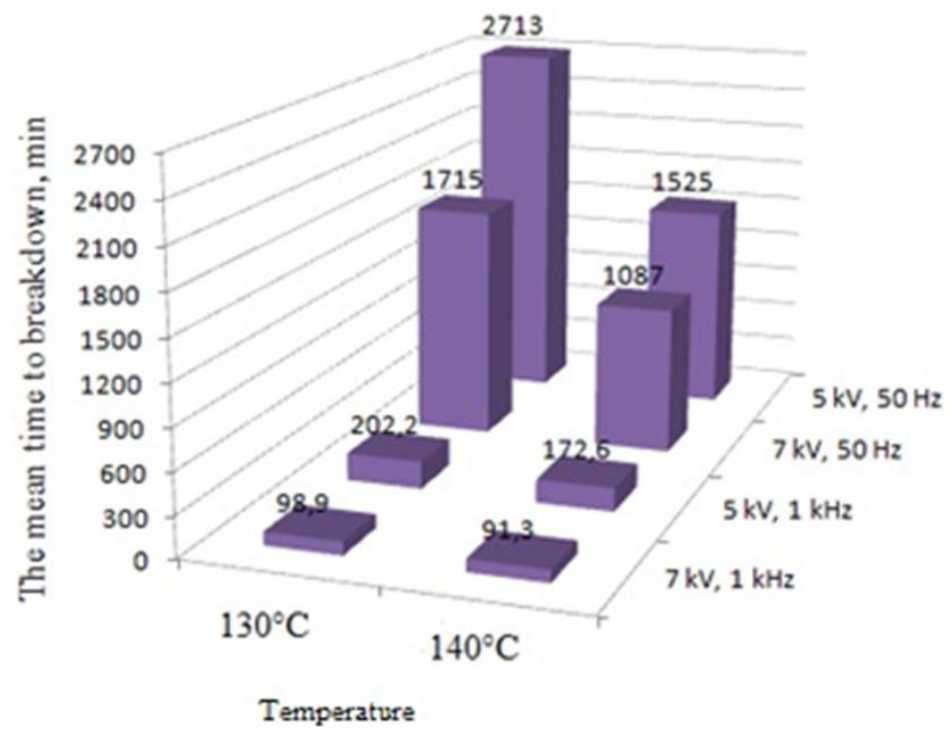

Fig. 1. The results of the mean time to breakdown of the insulation twists (block copolymer insulation).

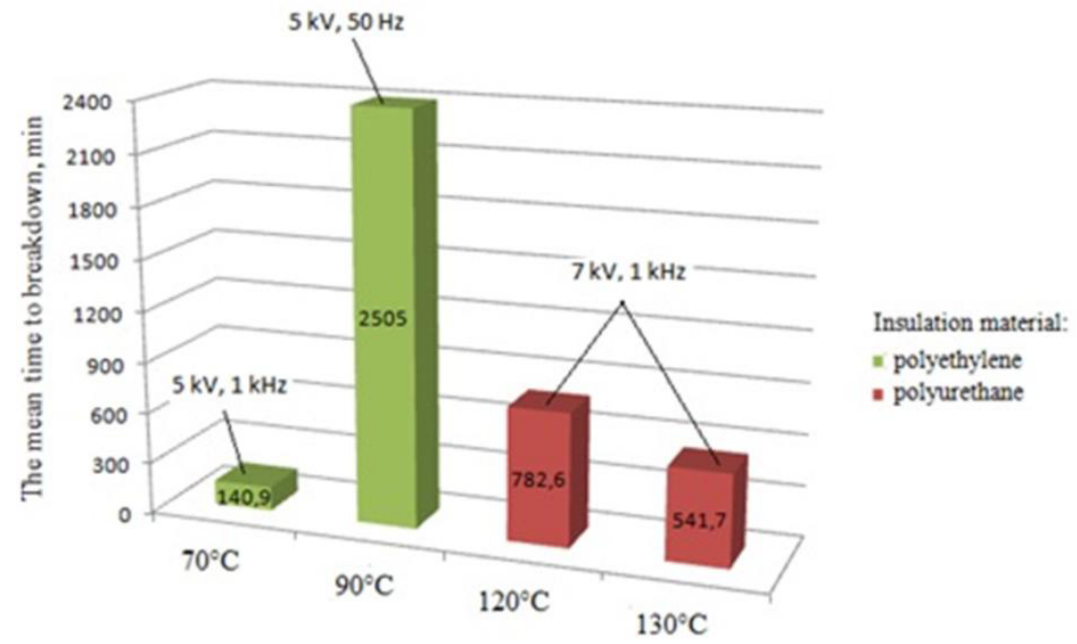

Temperature

Fig. 2. The results of the mean time to breakdown of the insulation prototypes. 
For polymeric insulation noted that the increase in frequency, intensity increases abruptly discharges and reduces the mean time to breakdown, leading to insulation breakdown.

\section{Conclusion}

Analyzing the results obtained are the following:

1.Hanging frequency of the applied field dramatically reduces mean time to breakdown, due to the fact that the increased heterogeneity of the field, there are discharges, which accelerates the process of electro-thermal aging of insulation.

2.Increasing the level of exposure to electric voltages greater impact on reducing the mean time to breakdown of the insulation than the temperature rise. The intensity of the electric aging prevails over the heat, thereby accelerates the process of destruction of the insulation.

3. Such tests allow to adequately assess the insulation resistance of cable products to the electro-thermal load and select materials for the insulation of VFD cables.

In future completion of the experimental setup and the definition of insulation resistance to high-frequency modulated load, both during the operation of the variable frequency drive.

\section{References}

1. A. Garganeev, A. Leonov, V. Merkulov, D. Charkov, IOP Conf. Ser.: Mater. Sci. Eng., 135, 012013 (2016)

2. C. Rodriguez Valdez, R. M. Tallam, R. J. Kerkman, Electro/Information Technology, 2008. EIT 2008. IEEE International Conference on, 151 (2008)

3. Leon M. Tolbert, Fang Zheng Peng, Thomas G. Habetler. IEEE Trans. Ind. Appl. 35, 36 (1999)

4. Jaroslaw Luszcz. Industrial Electronics (ISIE), 2011 IEEE International Symposium on. 538 (2011) 